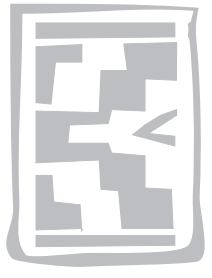

\title{
Studies on effects of lactose on experimental Trypanosoma vivax infection in Zebu cattle. 1. Plasma kinetics of intravenously administered lactose at onset of infection and pathology
}

\author{
M.Y. FATIHU ${ }^{1 *}$, S. ADAMU ${ }^{1}$, I.A. UMAR ${ }^{2}$, N.D.G. IBRAHIM ${ }^{1}$, L.O. EDUVIE ${ }^{3}$ \\ and K.A.N. ESIEVO ${ }^{1}$
}

\begin{abstract}
FATIHU, M.Y., ADAMU, S., UMAR, I.A., IBRAHIM, N.D.G., EDUVIE, L.O. \& ESIEVO, K.A.N. 2008. Studies on effects of lactose on experimental Trypanosoma vivax infection in Zebu cattle.1. Plasma kinetics of intravenously administered lactose at onset of infection and pathology. Onderstepoort Journal of Veterinary Research, 75:163-172
\end{abstract}

Lactose in normal saline was administered intravenously to a group of Zebu cattle infected with Trypanosoma vivax to determine the blood plasma kinetics at onset of an experimental infection and its ability to protect tissues against damage as part of preliminary studies to determine its suitability for use in the treatment of trypanosomosis. Significantly $(P<0.01)$ higher lactose concentrations were observed in the T. vivax-infected bulls at $30 \mathrm{~min}$ and $1 \mathrm{~h}(P<0.05)$ post-infection (p.i.) and by $4 \mathrm{~h}$ p.i. the plasma lactose remained above the level prior to infusion, after which it fell slightly below the preinfusion level in the uninfected group. Calculated pharmacokinetic parameters revealed delayed excretion of lactose in the $T$. vivax-infected group soon after infection. The total body clearance $\left(\mathrm{Cl}_{B}\right)$ was significantly $(P<0.05)$ reduced. The biological half-life $\left(t_{1}\right)$, elimination rate constant $\left(k_{e}\right)$ and apparent volume of distribution $\left(V_{d}\right)$ were relatively decreased $(P>0.05)$ as a result of the $T$. vivax infection. Retention of lactose in the plasma was attributed to decreased plasma clearance. It is suggested that the presence of trypanosomes in circulation rather than organic lesions could have been responsible for the delay observed in the excretion of lactose.

At 12 weeks p.i., when the experiment was terminated, the group infected and given lactose infusion (despite higher parasitaemia) had no gross or histopathological lesions in the brain, spleen, lymph nodes, heart, kidneys, liver and testes. However, the group infected but not infused with lactose were emaciated, had pale mucosae, watery blood, general muscular atrophy, serous atrophy of coronary fat and other adipose tissue, hepatomegaly, splenomegaly, swollen and oedematous lymph nodes, all of which are suggestive of trypanosomosis. Histopathological lesions included narrowing of Bowman's space and hypercellularity of glomerular tufts in the kidneys with the mean glomerular tuft nuclear indices (GTNs) in the group significantly higher $(P<0.01)$ than the mean GTNs of the lactoseinfused and control bulls. Degenerative changes occurred in the myocardium, spleen, testes and epididymides. The tesicular and epididymal lesions are indicative of male reproductive dysfunction.

Keywords: Cattle, lactose, pathology, plasma kinetics, Trypanosoma vivax

* Author to whom correspondence is to be directed. E-mail: myfatihuy@yahoo.com

1 Department of Veterinary Pathology and Microbiology, Ahmadu Bello University, Zaria, Nigeria

2 Department of Biochemistry, Ahmadu Bello University, Zaria, Nigeria

3 National Animal Production Research Institute, Ahmadu Bello University, Zaria, Nigeria

Accepted for publication 21 April 2008-Editor

\section{INTRODUCTION}

Trypanosomoses are important parasitic protozoal diseases of humans and animals that is prevalent throughout the tropical and sub-tropical parts of the world. In Africa, the form of the disease known as African animal trypanosomosis or nagana is an important constraint, if not the most important constraint, to livestock and mixed crop-livestock farming in tropical parts of the continent where its vector, 
flies of the genus Glossina known as tsetse flies, occur (Kristjanson, Rowlands, Swallow, Kruska, De Leew \& Nagda 1999). The current methods involved in the control of this disease in the absence of vaccines, include chemotherapy, breeding livestock that are trypanotolerant, reducing the proximity of livestock to the vectors, controlling the population of vectors by using insecticides or insect traps (Holmes 1997). Chemotherapy is the most widely used means of controlling this disease (Itard 1989; Geerts \& Holmes 1998). The development of trypanocidal drugs has been very slow (FAO 1979) which compounds the problems of drug resistance, limited range of available substances and drug toxicity (Connor 1992). These make the search for new trypanocides imperative.

Lactose is a disaccharide consisting of glucose and galactose, and is used in the pharmaceutical industry as a diluent, bulking agent, filler or excipient (Reynolds 1993) and has been suggested for use as a potential excipient for trypanocidal drugs (Esievo, Omage, Ibrahim, Umar \& Saror 1994). Lactose infusion has ameliorated serum biochemical changes (Kadima, Gyang, Saror \& Esievo 2000) in the acute stage of bovine trypanosomosis. Further studies are required on the efficacy and safety of lactose in this regard. The pharmacokinetics of trypanocides are incompletely understood, but the rate of excretion of the different compounds is known to affect their activity (Connor 1992). This paper reports the plasma kinetics of lactose following a single intravenous (i.v.) infusion at the commencement of Trypanosoma vivax infection in Zebu bulls.

Wide-spread pathological lesions in the body organs occur during animal trypanosomoses, including degenerative and necrotic changes (Hornby 1921; Fiennes 1970; Naylor 1971a, b; Isoun \& Esuruoso 1972; Murray, Murray, Jennings, Fischer \& Urquhart 1974; Valli, Forsberg \& Robinson 1978; Valli \& Forsberg 1979; Saror 1980). The combination of anaemia and severe lesions in the heart which are characterized by an inflammatory process with mononuclear cellular infiltration in the epicardium, myocardium and endocardium in $T$. vivax-infected Zebu cattle, may interfere with effective delivery of nutrients. These were suggested as being contributory factors to the occurrence of the emaciation which occurs in chronic trypanosomosis (Sannusi 1979).

\section{MATERIALS AND METHODS}

\section{Experimental animals}

Sixteen White Fulani Zebu bulls aged between 3 and 4 years, weighing between 120 and $200 \mathrm{~kg}$ were purchased from Anchau in the Kubau Local Government Area of Kaduna State, which is located in a tsetse fly-free zone of northern Nigeria. The animals had no record of exposure to trypanosome infection. On arrival at Zaria, also a tsetse fly-free zone where the experiment was carried out, the animals were acclimatized for at least 3 months during which they were dewormed with albendazole (Pantex Holland B.V.) and sprayed with chlorphenvinphos (Pfizona, Pfizer) for the control of external parasites. The animals were kept in sheds, grazed daily and given groundnut hay supplement. Water was provided ad libitum. Blood samples were collected and screened for haemoparasites before commencement of the experiment.

\section{The parasites}

A primary isolate of $T$. vivax was obtained from a naturally infected cow in Kudaru, Lere Local Government Area of Kaduna State. The infection was confirmed to be caused by pure $T$. vivax infection by the Department of Veterinary Parasitology and Entomology, Ahmadu Bello University, Zaria. A donor bull was inoculated i.v. with $5 \mathrm{ml}$ of the infected cow blood. The parasitaemia was monitored regularly up to the peak level.

\section{Preparation of lactose infusion solution}

A $50 \%$ lactose solution for infusion was prepared by dissolving $50 \mathrm{~g}$ of lactose in $100 \mathrm{ml}$ physiological saline $(0.9 \%$ sodium chloride) and warmed gently. The lactose solution was filtered into injection bottles, plugged and autoclaved at $120^{\circ} \mathrm{C}$ under 103 421.4 Pa pressure for $5 \mathrm{~min}$ and cooled to room temperature. Prior to every intravenous infusion, the lactose solutions were warmed to body temperature.

\section{Experimental procedure}

The experimental bulls were divided into four groups of four animals each and housed separately. Blood samples were collected from each bull prior to infection to determine the pre-infusion/pre-infection lactose level in the plasma of the lactose-infused groups.

\section{Group A}

Each of the bulls in this group was infected intravenously with $6 \mathrm{~m} \ell$ of donor bull's blood when it had reached its peak level of parasitaemia and contained $3 \times 10^{6}$ trypanosomes. Lactose infusion was 
given immediately after infection at a dose of $0.5 \mathrm{~g}$ lactose per $\mathrm{kg}$ body mass. Blood samples $(5 \mathrm{ml})$ were collected from each bull in McCartney bottles containing ethylenediamine tetra-acetic acid (EDTA) as anticoagulant, at 30 min intervals for $4 \mathrm{~h}$. The plasma was harvested and stored at $-18^{\circ} \mathrm{C}$.

\section{Group B}

These were the uninfected group, in which the animals were treated with lactose and blood samples were collected as were those in Group A.

\section{Group C}

Each bull in this group was infected with $T$. vivax as were those in Group A. However, they were not given any lactose treatment.

\section{Group D}

These were the normal control bulls that were neither infected nor given lactose treatment.

\section{Assay of plasma lactose}

Plasma lactose concentrations were assayed by the method of Wahba (1965), after interfering substances had been removed by differential binding in an ion-exchange column. Briefly, the procedure entailed preparation of microcolumns by recharging diethylaminoethyl cellulose (DEAE-cellulose, Sigma, UK) in $0.1 \mathrm{M}$ hydrochloric acid, washing it thoroughly in distilled water, and then in phosphate buffered saline (PBS) until the filtrate was neutral $(\mathrm{pH} \mathrm{7.0)}$. The washed DEAE-cellulose was resuspended in PBS and $1 \mathrm{ml}$ each was dispensed into cotton-plugged dropping pipettes and allowed to drain. The plasma was deproteinized using zinc acetate solution (2\% w/v) (Wahba 1965) and passed through the DEAEcellulose columns. The flow-through was collected and analysed for lactose.

\section{Data analysis}

The plasma lactose concentrations versus time were plotted on both linear and semi-log graphs. The regression lines were calculated (Harper 1991) and drawn. The following pharmacokinetic parameters were calculated from the semilogarithmic curves (Baggot 1977; Grahame-Smith \& Aronson 1984): the biological half-life $\left(t_{1 / 2}\right)$ was the time taken for the body (plasma) to eliminate one half of the lactose it contained; the apparent volume of distribution $\left(V_{d}\right)$ was the volume of fluid required to contain the amount of lactose in the body, when uniformly dis- tributed at a concentration equal to that of plasma; total body clearance $\left(\mathrm{Cl}_{B}\right)$ was the volume of body fluid cleared of lactose per unit time and the elimination rate constant $\left(k_{e l}\right)$ was the amount of lactose eliminated from the body via all routes (kidneys and urine in the case of lactose) per unit time. The statistical analysis for test of significance of differences between the means of the two groups was done using student's $t$-test (Philips 1978).

The mean values \pm standard error of mean (SEM) of the GTNs were subjected to statistical analysis using one-way analysis of variance (ANOVA) and Tukey-Kramer multiple comparison tests for any significant difference between the groups.

\section{Pathological studies}

The bulls in all the groups were sacrificed on day 13 post-infection (p.i.) for post-mortem examination. Their organs were examined for gross pathological changes and tissue specimens taken from all the major organs and fixed in $10 \%$ neutral buffered formalin for at least $48 \mathrm{~h}$ (Bush 1975). The tissues were dehydrated in ethanol and embedded in paraffin. Sections for microscopy were made at $5 \mu \mathrm{m}$ and stained with haematoxylin and eosin (HE) stain. Microscopic examinations of organs were conducted on brain, heart, kidney, liver, lymph node, spleen, testis and epididymis. The glomerular tuft nuclear indices (GTNs) (Dargantes, Campbell, Copeman \& Reid 2005) of the kidneys of the animals in Groups $A, C$ and $D$ were determined in order to assess the degree cellularity of the glomerular tufts.

\section{RESULTS}

The pre-infusion plasma lactose levels in the $T$. vivax-infected (Group A) bulls ranged from 0.33 to $2.94 \mathrm{mM}$ with a mean of $1.63 \pm 0.53 \mathrm{mM}$. In the uninfected (Group B) bulls, it ranged from 1.1 to $2.48 \mathrm{mM}$ with a mean of $1.79 \pm 0.33 \mathrm{mM}$. The mean plasma lactose concentration in the $T$. vivax-infected group was significantly higher $(P<0.01)$ by 30 min and $(P<0.05)$ at $1 \mathrm{~h}$ post-infusion, when compared to the mean levels in the uninfected group. Furthermore, the mean lactose concentration in the infected group remained above the pre-infusion concentration by $4 \mathrm{~h}$ post-infusion, compared to lactose concentration in the uninfected group which fell to below the pre-infusion level during the same period (Fig. 1). The mean values of pharmacokinetic parameters obtained in both groups are presented in Table 1. 
Effects of lactose on experimental Trypanosoma vivax infection in Zebu cattle. 1

TABLE 1 Pharmacokinetic parameters (mean \pm SEM) of lactose in Trypanosoma vivax-infected and uninfected control Zebu bulls

\begin{tabular}{|l|c|c|}
\hline Pharmacokinetic parameter & $\begin{array}{l}\text { Infected bulls } \\
(\boldsymbol{n}=\mathbf{4})\end{array}$ & $\begin{array}{l}\text { Uninfected bulls } \\
(\boldsymbol{n}=\mathbf{4})\end{array}$ \\
\hline$t_{1 / 2}(\mathrm{~h})$ & $6.3 \pm 1.08$ & $3.48 \pm 0.80$ \\
$V_{d}\left(\ell \mathrm{kg}^{-1}\right)$ & $26.025 \pm 2.929$ & $46.707 \pm 8.629$ \\
$C l_{B}\left(\ell \mathrm{kg}^{-1} \mathrm{~h}^{-1}\right)$ & $* 3.26 \pm 0.63$ & $* 10.54 \pm 2.53$ \\
$K_{e l}\left(\mathrm{~h}^{-1}\right)$ & $0.567 \pm 0.085$ & $0.737 \pm 0.157$ \\
\hline
\end{tabular}

* $\quad$ Significant difference $(P<0.05)$

$t_{1 / 2} \quad$ Biological half-life

$C l_{B}$ Apparent volume of distribution

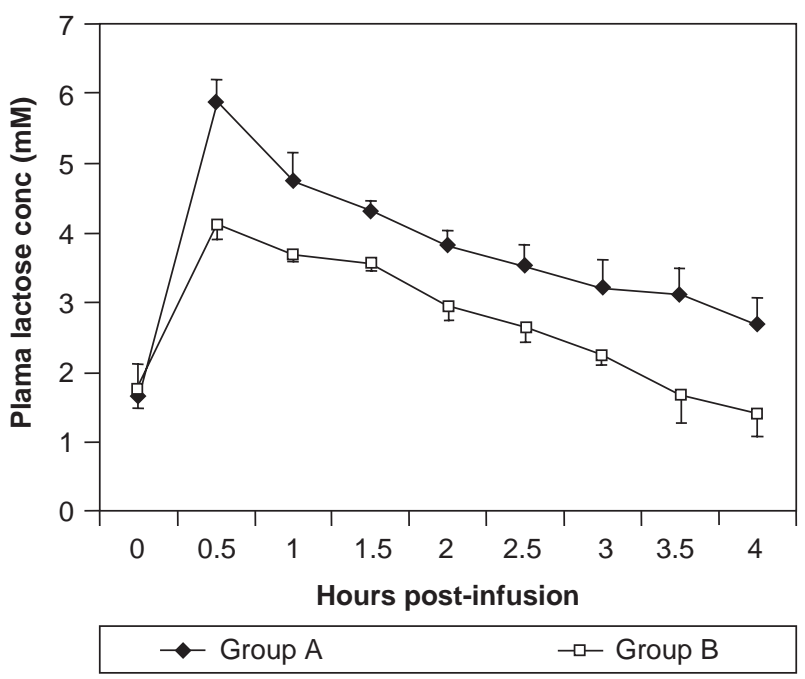

FIG. 1 Mean ( \pm SEM) Plasma lactose concentrations in Zebu bulls infected with Trypanosoma vivax (Group A) and in the uninfected control (Group B) after a single dose

\section{Macroscopical pathology}

\section{Group C}

The bulls in this group showed a variable degree of emaciation, rough hair coat, pallor of the mucosae and a watery blood. There was general muscular atrophy, serous atrophy of coronary and other adipose tissue, hepatomegaly, splenomegaly, and swollen and oedematous lymph nodes. The hearts, brains and testes showed no gross lesions.

\section{Group A}

There were no significant gross lesions observed.

\section{Group D}

No gross lesions were observed.

\section{Histopathology}

The following is a composite picture of the more prominent pathological changes encountered in the bulls.
$K_{e l} \quad$ Elimination rate constant

$V_{d} \quad$ Volume of distribution

\section{Group C}

LIVER: There were fatty change and coagulative necrosis of hepatocytes, and conspicuous and swollen Kupffer cells contained phagocytosed erythrocytes (Fig. 2).

KIDNEYS: The observed lesions included enlargement and hypercellularity of glomerular tufts, narrowing of Bowman's space (Fig. 3). The mean GTNs in the group was $88.72 \pm 2.12$ which is significantly higher $(P<0.01)$ than the mean GTNs of the infected, lactose-infused (Group A) and normal control (Group D) bulls.

HEART: There was degeneration of myocardial fibres and interstitial oedema (Fig. 4).

SPLEEN: Depletion of lymphoid cells in the central zones and necrosis of the lymphoid cells of the peripheral zone of the white pulp. Erythrophagocytosis and haemosiderin pigments were observed in the macrophages of the red pulp (Fig. 5).

LYMPH NODES: These showed reduction in cells of lymphoid follicles in the cortex and oedema mainly involving the cortex and paracortical regions.

TESTES: The seminiferous tubules showed degeneration and decrease in spermatogenic cells with scanty spermatids and degeneration of Sertoli cells in the tubules. Interstitial (Leydig) cells showed variable degrees of degeneration (Fig. 6).

EPIDIDYMIDES: There was necrosis of epididymal epithelial cells and absence of microvilli (stereocilia). Many segments of the duct contained no spermatozoa (Fig. 7).

BRAIN: The cerebellum had degenerating neurones in the Purkinje cell and granular layers (Fig. 8).

\section{Group A}

LIVER: There was mild congestion in the sinusoids and absence of erythrophagia by Kupffer cells (Fig. 9). 

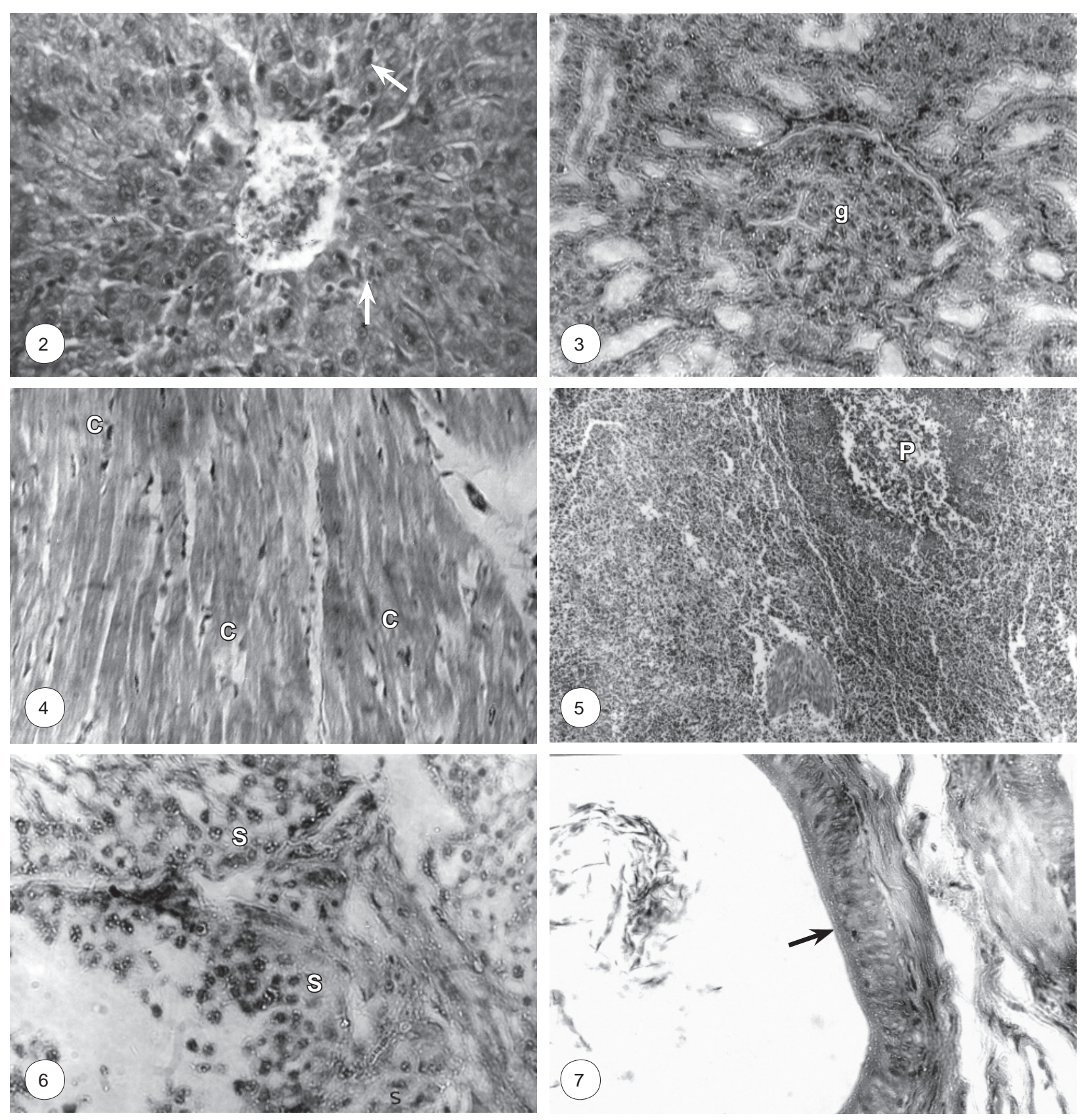

FIG. 2 Photomicrograph of liver from a T. vivax-infected bull not infused with lactose. Note erythrophagia by Kupffer cells (arrows) and fatty change. $\mathrm{H} \& \mathrm{E} ; \mathrm{X} 357$

FIG. 3 Photomicrograph of kidney of a T. vivax-infected bull, not infused with lactose. The Bowman's space is obliterated as a result of a proliferation of the mesangium of the glomerulus $(\mathrm{g})$. $\mathrm{H} \& \mathrm{E} ; \mathrm{X} 300$

FIG. 4 Photomicrograph of the heart of a T. vivax-infected, uninfused bull, showing degeneration of myocardial fibres (c). H \& E; X300

FIG. 5 Photomicrograph showing the spleen of a T. vivax-infected, uninfused bull. There is depletion of lymphoid cells from white pulp nodule $(P) . H$ \& E; X105

FIG. 6 Photomicrograph of the testis of a T. vivax-infected, uninfused bull, showing degeneration of interstitial cells and spermatogenic cells (S) in seminiferous tubules. $\mathrm{H} \& \mathrm{E} ; \mathrm{X} 357$

FIG. 7 Photomicrograph of the epididymis of a T. vivax-infected, uninfused bull. Note absence of microvilli (stereocilia) on the epithelial surface (arrow) and decreased sperm reserve. H \& E; X357 